\title{
THE INFLUENCE BY THE SURFACE TEXTURE OF CUTTING TOOLS ON METAL CUTTING PERFORMANCE
}

\author{
Yin Jiahui ${ }^{1}$, Wang Dazhong ${ }^{2}$ \\ ${ }^{1}$ Shanghai University of Engineering Science, School of Mechanical Engineering, Shanghai, 201620 \\ ${ }^{2}$ Shanghai University of Engineering Science, School of Mechanical Engineering, Shanghai, 201620
}

\begin{abstract}
The surface texture cutting tools has excellent cutting performance in the metal cutting process, which can better reduce the cutting force and cutting heat in the cutting process. In this paper, we use the CBN tools to cut the AISI 1045 material by the finite element simulation method. Taguchi method is used to study surface texture tools of different sizes. Simulation studies are conducted by changing the width, depth and spacing of the tool texture. We consider the size combination of the width, depth and spacing of the surface texture, and select a more appropriate size parameter. The width of surface texture has the greatest influence on the temperature and stress distribution of metal cutting.
\end{abstract}

Keywords: - Tool surface texture $\cdot$ Taguchi method $\cdot$ size of texture $\cdot$ cutting performance

\section{INTRODUCTION}

Recently, the surface texture tools have drawn the public attention. At the same time, dry cutting also become more and more important, which can decrease the cutting fluid pollution and the cutting fluid waste in the world. However, dry cutting will lead to high friction and high adhesion at the chip-tool interface [1-5].

Researchers did many experiments to study the textured tool in the cutting performance. For example, Sugihara et al did many researches to study the texture tools. In 2013[6], they studied the cutting tools with various textured surfaces to increase cutting tool life. The result showed that the newly developed tool having the textured flank face significantly reduced the flank wear by the face milling experiments on steel material. In 2016[7], they did a series of cutting experiments to study the dimple textures. Their researches significantly improved the crater wear resistance and the tribological behavior on the tool rake face, and they exhibited a superior performance compared with those with groove textures, especially in a severely lubricated environment. In 2017[8], they did some experiments to prove that the cubic boron nitride cutting tool with a texture flank face to cut Inconel 718 at a high speed. Their experiments conformed that the novel cutting tool can improve the tool life.

Deng et al. did many experiments to research textured tools cutting performance. In 2013, they experimentally investigated that the carbide tools rake face with the nanoscale surface texture made by femtosecond laser could improve the cutting performance and the rake face surface texture was filled with WS2 solid lubricant also could reduce the tool wear [9]. In 2014, they used the Al2O3/TiC ceramic tools of the nanoscale and microscale texture to study the cutting performance in the dry cutting environment. Experimental research showed that the cutting tool could improve cutting performance, reduce cutting force, cutting temperature and friction coefficient. At the same time, the use of self-lubricated tool could reduce tool wear and improve the service life of tool [10]. In 2015, they used the texture cutting tool with the TiAIN layer to research the cutting performance under different lubrication conditions. Experimental research showed that when the cutting speed in the $200 \mathrm{~m} / \mathrm{min}$, microscale texture cutting tool with the TiAIN layer became liquid lubricant formed secondary lubrication, reduced the tool wear [11]. In 2016, they used an Nd:YAG laser to fabricate two different spacing textured ceramic tools. Results showed that the texture morphology and spacing have a significant influence on the tribological properties. The sample with small texture spacing might be beneficial to increasing the friction coefficient, and the wavy-grooved sample exhibits the highest friction coefficient and shallowest wear depth [12]. In 2017, they used carbide tools to cut green alumina cermics in dry condition. The derivative cutting was found that the flank-face texture can decrease of the flank wear of tools and storage powder chip [13]. They also used textured tools to cut AISI 1045 without lubricants. Results showed that the workpiece cut by the micro-textured tools would lead to derivative cutting. The derivative cutting would lead to the increase of friction at the tool-chip interface, cutting forces, hardness, and deformation of chip [14].

In addition, many researchers have studied the cutting performance of surface texture cutting tool from different aspects. Ma et al. [15] compared the experiments and the finite element analysis found that the surface of the cutting tools with a microbumps structure can reduce the cutting force and reduce the chip-tool interface. Johannes et al. [16] used the uncoated cemented carbide tools to study the 
different influence on the behaviour of built-up edge formation and wear evolution over the cutting length after defined dry straight turning. The result of their study confirmed that the adhesion of workpiece material on the rake face can be modified with respect to an untextured cemented carbide cutting tool in the dry cutting tool in the dry metal cutting process by applying specific textures produced by laser texturing. Su et al. [17] studied the cutting performance of micro-textured polycrystalline diamond tool in dry cutting. They found that the tribological properties of the tool-chip interface were better in the textured cutting tools. Rodrigo L et al. [18] did some experiments to find that the interactions between the chip and structured rake face depend on the chip formation. Zhenglong Fang et al. did the experiments to find that the function of micro-textures for increasing the turbulent kinetic energy and cooling the textured tool face [19]. Vasumathy et al. [20] did the research to study the texture tools. Result showed that the texture modifies the adhesion of chips on the rake face as compared to the conventional tool and reduces the cutting forces. Roshan Sasi [21] studied the laser surface textured tools. Roshan Sasi et al. found that textured high-speed steel tools can significantly improve the metal cutting process while dry machining ductile workpieces.
This paper mainly studies the influence of different surface texture sizes on cutting performance. The texture cutting tools of different sizes are studied by means of finite element simulation. We studied the cutting performance by the cutting temperature, cutting force and stress field. Through the comparative analysis of the literatures, in the selection of the shape of the tool's surface texture, we adopt a relatively simple circular texture with excellent cutting effect. Through the study of the reference [22], the dimension parameters of texture are set as follows: the depth of the texture tool were 10,15 and 20 microns, the width were 60,80 and 100 microns, and the spacing were 10,20 and 30 microns.

\section{NUMERICAL SIMULATION}

\subsection{Workpiece and Tool}

The workpiece dimension is $5 \mathrm{~mm}$ in length and $2 \mathrm{~mm}$ in height. The upper right corner of the workpiece is located at the origin. We can see the 2D FEM machining model in Fig.1. The material of the workpiece is AISI 1045 steel and the material property of the AISI 1045 is given in table 1 . The material of the tool is CBN. The cubic boron nitride is synthesized from hexagonal boron nitride and catalyst under high temperature and pressure. It is a new high-tech product after the invention of synthetic diamond.

Table 1: Material properties of the workpiece and tool

\begin{tabular}{|l|l|l|}
\hline Material properties & AISI 1045 & CBN \\
\hline Density (kg m-3) & 7800 & \\
\hline Poisson's Ratio & 0.3 & 0.11 \\
\hline Conductivity $\left(\mathrm{W} \mathrm{m}-1^{\circ} \mathrm{c}-1\right)$ & 44.5 & 140 \\
\hline Inelastic Heat Fraction & 0.9 & \\
\hline Thermal Specific Heat $\left(\mathrm{J} \mathrm{kg}-1^{\circ} \mathrm{c}-1\right)$ & 420 & 670 \\
\hline Thermal expansion coefficient $\left({ }^{\circ} \mathrm{c}-1\right)$ & $1.2 \mathrm{E}-6$ & $4.7 \mathrm{E}-6$ \\
\hline
\end{tabular}

We choose the $\mathrm{J}-\mathrm{C}$ model to describe the plastic properties of the material and the parameters are given in table 2 . The $\mathrm{J}-\mathrm{C}$ model can reflect the thermal softening effect and work hardening effect in the process of machining and the strengthening effect of strain rate, thus is widely used in metal cutting process simulation. The constitutive equation of the $\mathrm{J}-\mathrm{C}$ model is as follows [23]:

$$
\sigma=(A+B \bar{\varepsilon})\left(1+C \ln \left(\frac{\dot{\bar{\varepsilon}}}{\dot{\overline{\varepsilon_{0}}}}\right)\right)\left(1-\frac{T-T_{\text {room }}}{T_{\text {melt }}-T_{\text {room }}}\right)
$$

In the formula, $\sigma$ is expressed as the flow stress, $\mathrm{A}$ and $\mathrm{B}$ are the yield strength and the stiffness modulus and the $\bar{\varepsilon}, \dot{\bar{\varepsilon}}$ and $\dot{\bar{\varepsilon}}_{0}$ are expressed as strain, strain rate and reference strain rate . In addition, the $\mathrm{T}$, Troom and Tmelt are expressed as the temperature of the workpiece, the room temperature and the melting point of the workpiece.

Table 2: J-C parameters for AISI 1045

\begin{tabular}{|l|l|l|l|l|}
\hline A (Mpa) & B (Mpa) & C & n & m \\
\hline 553.1 & 600.8 & 0.0134 & 0.234 & 1 \\
\hline
\end{tabular}

\subsection{Parameters of Tool Texture}

The circular texture is used to study the cutting performance of the cutting tools. Meanwhile, the Taguchi method is also used for comparative analysis of simulation. Its main analysis tool is the orthogonal table and signal-to-noise ratio. The Taguchi method compare with the traditional experimental method, Taguchi method can significantly reduce test times, shorten the experiment time and reduce cost.

In our research, the orthogonal test table have three factors and three levels. The width, depth and spacing of the tool texture are the influencing factors of this experiment. The definition of width, depth and spacing is shown in Fig. 1. Each factor has three levels, and the setting of specific parameters is shown in Table 3. The orthogonal experimental design is shown in table 4.

Table 3: Experimental influence factors and parameter setting

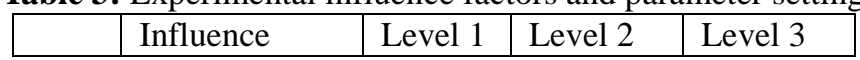




\begin{tabular}{|l|l|l|l|l|}
\hline & factors & & & \\
\hline A & Width $(\mu \mathrm{m})$ & 60 & 80 & 100 \\
\hline B & Depth $(\mu \mathrm{m})$ & 10 & 15 & 20 \\
\hline C & Space $(\mu \mathrm{m})$ & 10 & 20 & 30 \\
\hline
\end{tabular}

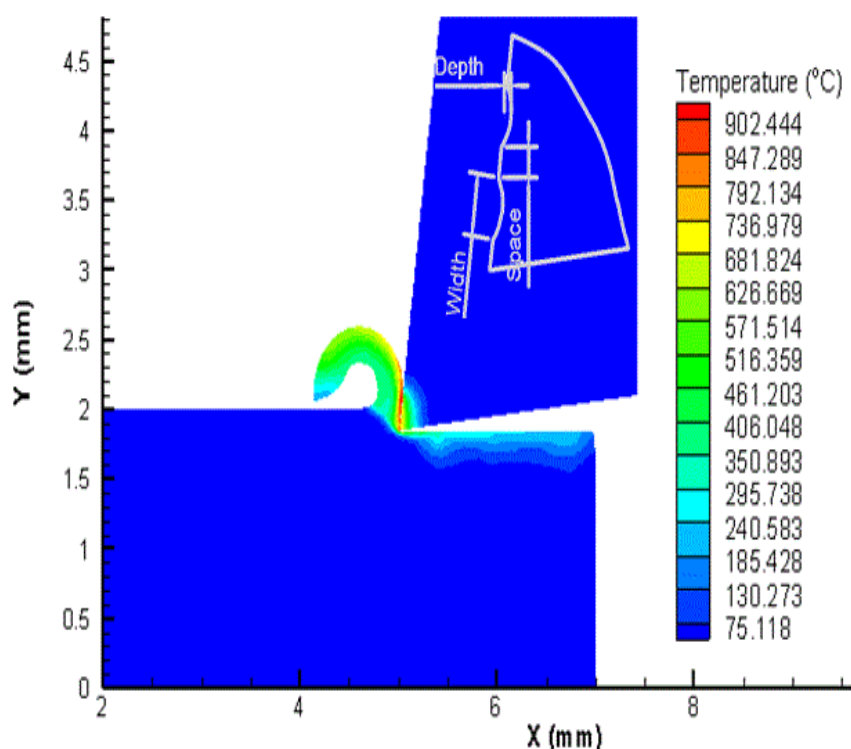

Fig 1: FEM machining model with the surface texture tool

Table 4: Orthogonal experimental design

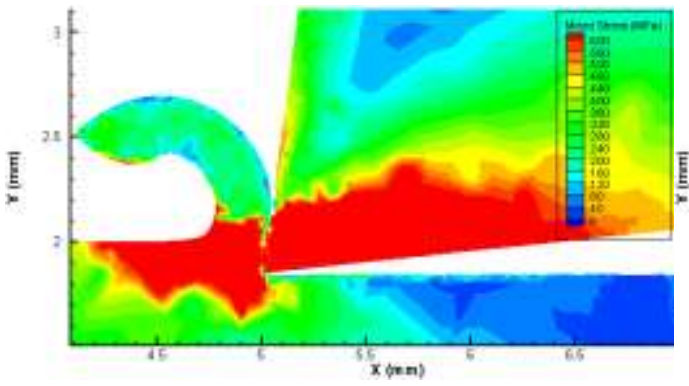

(a)

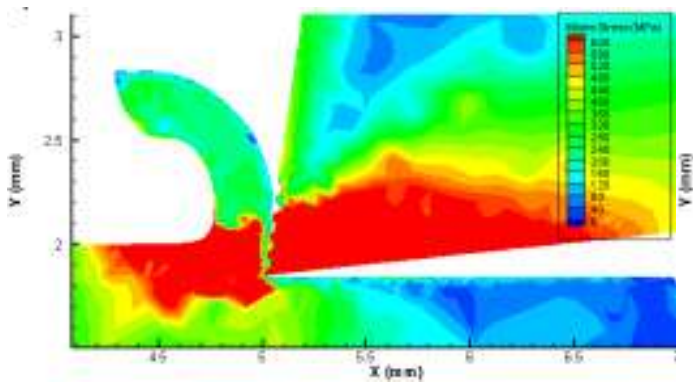

(c)

\begin{tabular}{|l|l|l|l|l|}
\hline $\begin{array}{l}\text { Experimental } \\
\text { number }\end{array}$ & Factor A & Factor B & Factor C & Error \\
\hline 1 & 1 & 1 & 1 & 1 \\
\hline 2 & 1 & 2 & 2 & 2 \\
\hline 3 & 1 & 3 & 3 & 3 \\
\hline 4 & 2 & 1 & 2 & 3 \\
\hline 5 & 2 & 2 & 3 & 1 \\
\hline 6 & 2 & 3 & 1 & 2 \\
\hline 7 & 3 & 1 & 3 & 2 \\
\hline 8 & 3 & 2 & 1 & 3 \\
\hline 9 & 3 & 3 & 2 & 1 \\
\hline
\end{tabular}

\section{RESULT AND DISCUSSION}

\subsection{The Effect of Mises Stress by the Different Surface Texture Size}

We carry on the comparative analysis from three aspects. Fig. 6 shows the stress distribution during the cutting process.

(1) When the width of texture is the same, the depth and spacing change. We found that during the cutting process, the stress of the cutting tools decreased, and the stress in the tool-chip contact area also decreased.

(2) When the texture depth is the same, the width and spacing change. There was no significant change in the stress of the tool and the tool-chip contact area during the cutting process.

(3) When the spacing of texture is the same, the width and depth change. It is found that the increase of width can reduce the overall force, and the deepening of depth can also change the force during the whole cutting process.

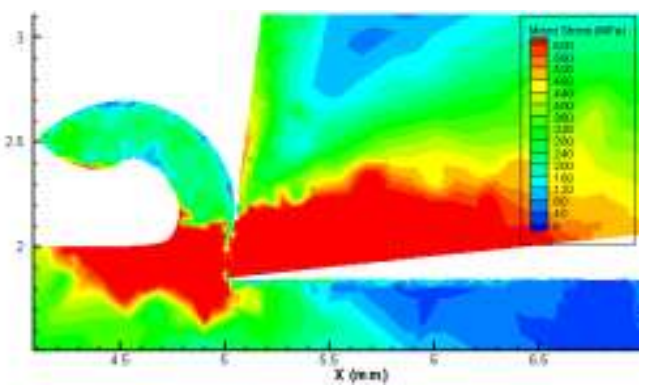

(b)

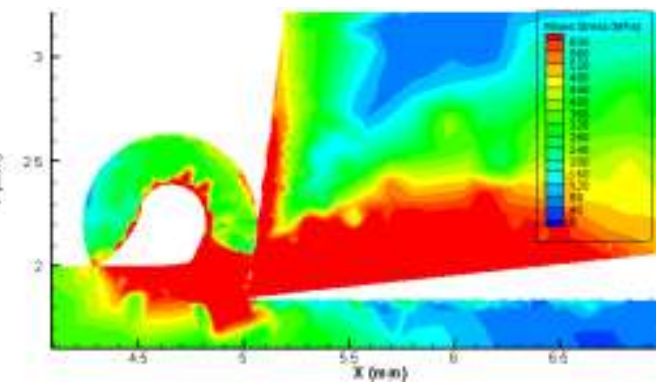

(d) 


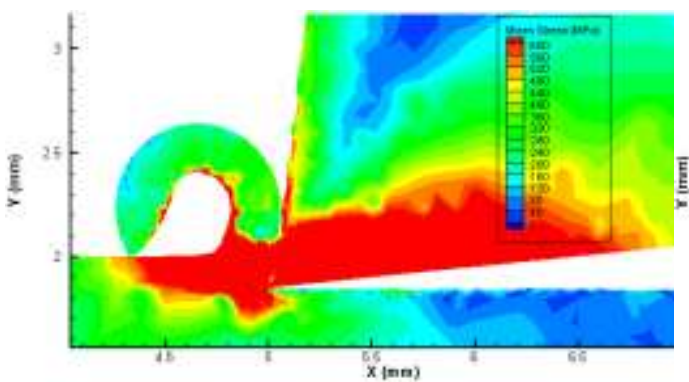

(e)

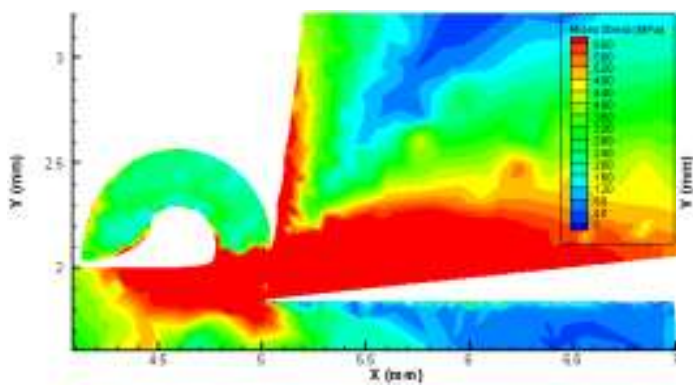

(g)

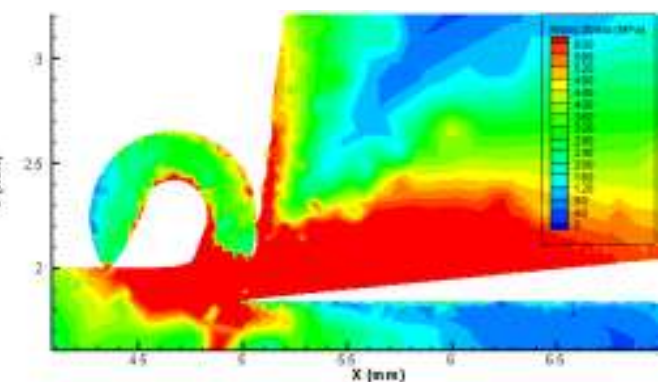

(f)

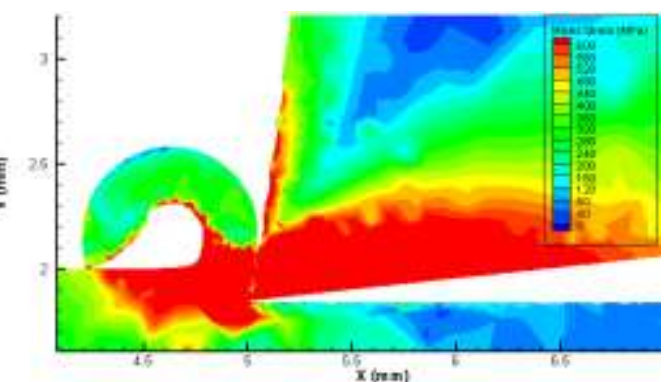

(h)

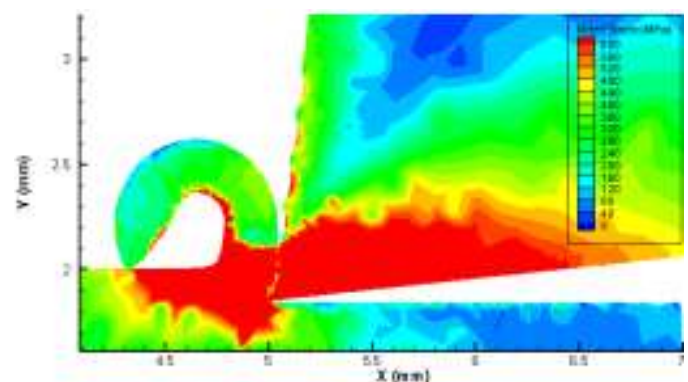

(i)

Fig 3: The cutting stress produced by different texture tools

Compared with (1), (2) and (3), results show that relative to the working situation, the depth of texture changes have bigger influence on the stress distribution, the second is the width of the texture, the last is the distance between texture.

The analysis of $\mathrm{S} / \mathrm{N}$ ratio of cutting force and temperature

The Taguchi method is used to study the effect of texture size on cutting forces during the cutting progress. There are three kinds of quality characteristics of the signal to noise ratio proposed by Taguchi Law, namely the large-scale characteristics, the expected characteristics and the small characteristics. In this experiment, the minimum cutting force was obtained through the optimization of the texture size parameters. The formula for calculating the minimum characteristics is [24]:

$$
\frac{\mathrm{S}}{\mathrm{N}}=-10 \log \frac{1}{\mathrm{n}}\left(\sum_{\mathrm{i}=1}^{\mathrm{n}} \mathrm{y}_{\mathrm{i}}^{2}\right)
$$

where $\mathrm{n}$ is the total number of measurements; yi is the measurement.

Table 5: Experimental results and $\mathrm{S} / \mathrm{N}$ ratio

\begin{tabular}{|l|l|l|l|l|l|l|l|}
\hline Experimental & $\mathrm{A}$ & $\mathrm{B}$ & $\mathrm{C}$ & $\mathrm{F} / \mathrm{N}$ & $\mathrm{T} /{ }^{\circ} \mathrm{C}$ & F for S/N Ratio & T For S/N Ratio \\
\hline 1 & 1 & 1 & 1 & 230 & 902 & -47.23 & -59.10 \\
\hline 2 & 1 & 2 & 2 & 235 & 1546 & -47.72 & -63.78 \\
\hline 3 & 1 & 3 & 3 & 240 & 1021 & -47.60 & -60.18 \\
\hline 4 & 2 & 1 & 2 & 210 & 843 & -46.44 & -58.52 \\
\hline 5 & 2 & 2 & 3 & 220 & 813 & -46.85 & -58.20 \\
\hline 6 & 2 & 3 & 1 & 220 & 803 & -46.85 & -58.09 \\
\hline
\end{tabular}




\begin{tabular}{|l|l|l|l|l|l|l|l|}
\hline 7 & 3 & 1 & 3 & 210 & 774 & -46.44 & -57.74 \\
\hline 8 & 3 & 2 & 1 & 220 & 765 & -46.85 & -57.67 \\
\hline 9 & 3 & 3 & 2 & 220 & 803 & -46.85 & -58.09 \\
\hline
\end{tabular}

Table 6: The $\mathrm{S} / \mathrm{N}$ ratio of the force

\begin{tabular}{|l|l|l|l|}
\hline & A & B & C \\
\hline Level 1 & -47.42 & -46.70 & -46.98 \\
\hline Level 2 & -46.71 & -47.10 & -46.96 \\
\hline Level 3 & -46.71 & -47.04 & -46.90 \\
\hline$\Delta$ & 0.71 & 0.4 & 0.08 \\
\hline $\begin{array}{l}\text { Ranking } \\
\text { importance }\end{array}$ & 1 & 2 & 3 \\
\hline
\end{tabular}

Table 7: The $\mathrm{S} / \mathrm{N}$ ratio of the temperature

\begin{tabular}{|l|l|l|l|}
\hline & A & B & C \\
\hline Level 1 & -61.02 & -58.45 & -58.29 \\
\hline Level 2 & -58.12 & -59.88 & -60.13 \\
\hline Level 3 & -57.83 & -58.79 & -58.79 \\
\hline$\Delta$ & 3.19 & 1.43 & 1.84 \\
\hline Ranking of importance & 1 & 3 & 2 \\
\hline
\end{tabular}

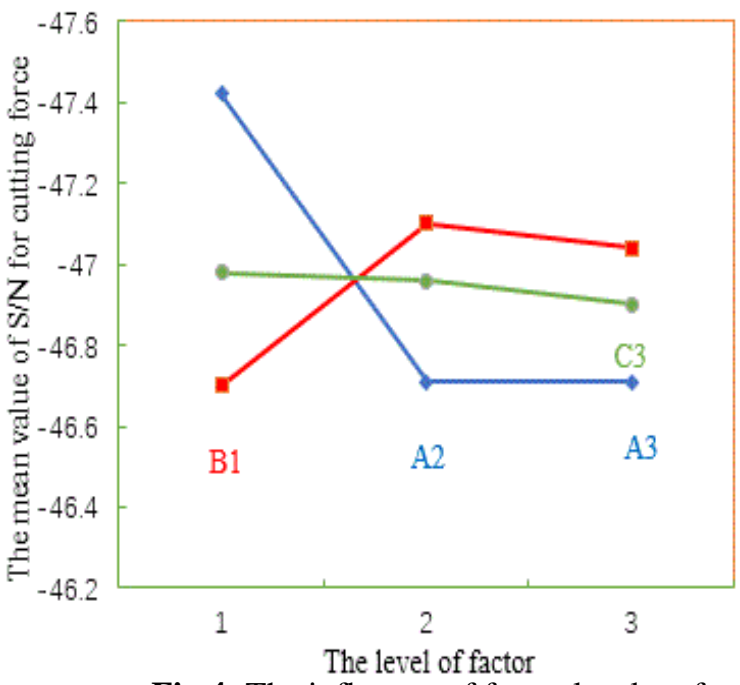

Fig 4: The influence of factor level on force

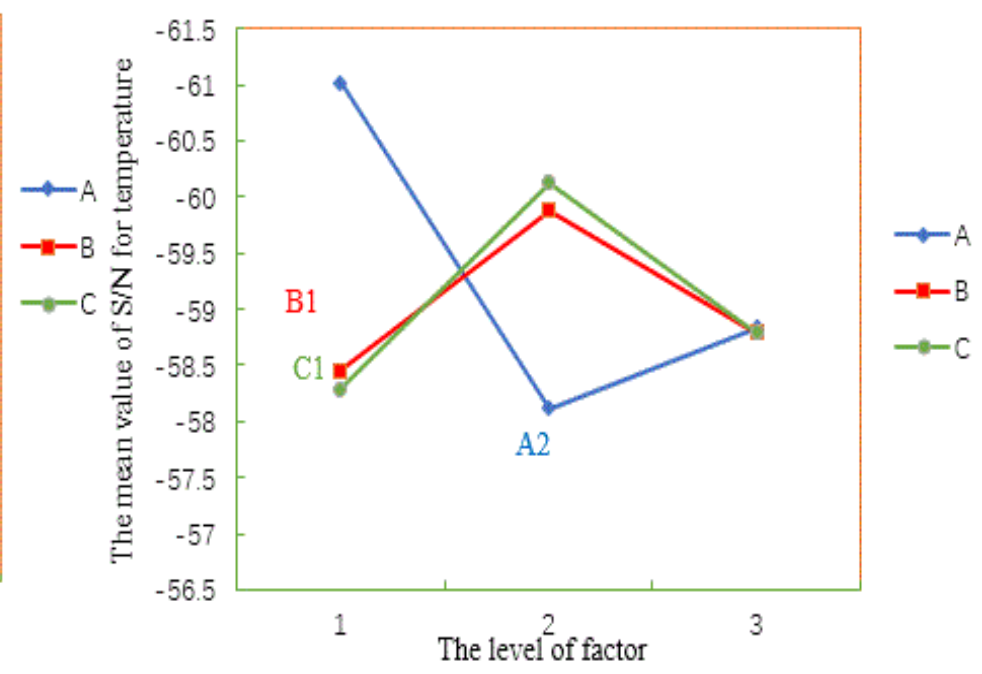

Fig 5: The influence of factor level on temperature
Table 5 and Fig. 4 show that the width, depth and spacing of the surface texture have different contribution to the ratio of $\mathrm{S} / \mathrm{N}$ on cutting force. The width of the surface texture has the greatest influence on the $\mathrm{S} / \mathrm{N}$ ratio. The increase of surface texture width can reduce the cutting force. With the increase of the space between the surface textures, the cutting force in the cutting process presents a downward trend. The increase of surface texture depth will lead to an increase in cutting force. According to the Taguchi method analysis, the higher the $\mathrm{S} / \mathrm{N}$ ratio, the better the performance evaluation index of the output. From Fig. 4, the optimal cutting parameter combination with the minimum cutting force are $\mathrm{A} 2 \mathrm{~B} 1 \mathrm{C} 3$ and $\mathrm{A} 3 \mathrm{~B} 1 \mathrm{C} 3$.
Tables 6 and Fig. 5 show that the width, depth and spacing of surface texture have different contribution to the ratio of $\mathrm{S} / \mathrm{N}$ on temperature. The width of the surface texture has the greatest influence on the $\mathrm{S} / \mathrm{N}$ ratio, and the $\mathrm{S} / \mathrm{N}$ ratio fluctuates with the change of the surface texture width. Relatively speaking, the increase of the depth and spacing of the surface texture leads to an increase in cutting temperature. According to the Taguchi method analysis, the higher the $\mathrm{S} / \mathrm{N}$ ratio, the better the performance evaluation index of the output. From Fig. 5, the optimal cutting parameter combination with the minimum cutting temperature is $\mathrm{A} 2 \mathrm{~B} 1 \mathrm{C} 1$. 


\section{CONCLUSION}

[9] Jianxin Deng, Yunsong Lian, Ze Wu, Youqiang Xing

In this study, the effect of texture size parameters on metal cutting performance was studied by using different size cutting tools. We have studied cutting stress distribution, the cutting temperature and cutting force. The results are as follows:

(1) In the process of metal cutting, the width of surface texture has the biggest influence on cutting temperature. The cutting temperature decreases with the increase of the width of surface texture. At the same time, the spacing of surface texture also has a certain influence on the temperature. As the spacing increases, the cutting temperature will rise.

(2) The variation of the parameters of the surface texture tool has great influence on the stress of the tool face. As the width of the texture becomes larger, the contact area of the tool-chip becomes larger, resulting in greater stress on the tool front surface.

According to the research of this paper, the surface texture parameters have different effects on cutting performance under different demands. Therefore, we must choose a reasonable surface texture size for cutting in order to achieve the best cutting results.

\section{REFERENCES}

[1] K. Poser, K.H. Zum Gahr, J. Schneider (2005). Development of $\mathrm{Al} 2 \mathrm{O} 3$ based ceramics for dry friction systems, J Wear 259:529-538

[2] J Ma, D NH uong, S Chang (2015). Assessment of microgrooved cutting tool in dry machining of AISI 1045 steel. J Journal of Manufacturing Science and Engineering 137:031001

[3] WM Da Silva, MP Suarez, AR Machado, HL Costa (2013). Effect of laser surface modification on the micro-abrasive wear resi stance of coated cemented carbide tools. J Wear 302(1-2):1230-40.

[4] X.B. Cui, J.X. Guo, J.X. Zheng (2016). Optimization of geometry parameters for ceramic cutting tools in intermittent turning of hardened steel. J Materials and Design 92:424-437.

[5] T. Pratap, K. Patra (2018). Mechanical micro-texturing of Ti-6Al-4V surfaces for improved wettability and bio-tribological performances. J Surface and Coatings Technology 349:71-81

[6] Tatsuya Sugihara, Toshiyuki Enomoto (2013). Crater and flank wear resistance of cutting tools having micro textured surfaces. J Precision Engineering 37:888-896

[7] Tatsuya Sugihara, Toshiyuki Enomoto (2016). Performance of cutting tools with dimple textured surfaces: a comparative study of different texture patterns. J Precision Engineering 49:52-60

[8] Tatsuya Sugihara, Toshiyuki Enomoto (2017). Development of a novel cubic boron nitride cutting tool with a textured flank face for high-speed machining of Inconel 718.J Precision Engineering 48:75-82
(2013). Performance of femtosecond laser-textured cutting tools deposited with WS2 solid lubricant coatings. J Surface \& Coatings Technology 222:135-143

[10] Youqiang Xing, Jianxin Deng, Jun Zhao, Guodong Zhang, Kedong Zhang (2014). Cutting performance and wear mechanism of nanoscale and microscale textured $\mathrm{Al} 2 \mathrm{O} 3 / \mathrm{TiC}$ ceramic tools in dry cutting of hardened steel. J Int. Journal of Refractory Metals and Hard Materials 43:46-58

[11] Kedong Zhang, Jianxin Deng, Youqiang Xing, Shipeng Li, Huanhuan Gao (2015). Effect of microscale texture on cutting performance of WC/Co-based TiAlN coated tools under different lubrication conditions. J Applied Surface Science 326:107-118

[12] Youqiang Xing, Jianxin Deng, Ze Wu, Fengfang Wu (2017). High friction and low wear properties of laser-textured ceramic surface under dry friction. J Optics and Laser Technology 93:24-32

[13] Yayun Liu, Jianxin Deng, Fengfang Wu, Ran Duan, Xiang Zhang, Yunhe Hou (2017). Wear resistance of carbide tools with textured flank-face in dry cutting of green alumina ceramics. J Wear 372-372:91-103

[14] Ran Duan, Jianxin Deng, Xing Ai, Yayun Liu, Hui Chen (2017). Experimental assessment of derivative cutting of micro-textured tools in dry cutting of medium carbon steels. J The International Journal of Advanced Manufacturing Technology 92:3531-3540

[15] Jianfeng Ma, Nick H. Duong, Shuting Lei (2015). Numerical investigation of the performance of microbump textured cutting tool in dry machining of AISI 1045 steel. J Journal of manufacturing Processes 19:194-204

[16] Johannes Kümmel, Daniel Brauna, Jens Gibmeiera, Johannes Schneidera, Christian Greinera, Volker Schulzea, Alexander Wanner (2015). Study on micro texturing of uncoated cemented carbide cutting tools for wear improvement and built-up edge stabilisation. J Journal of Materials Processing Technology 215:62-70

[17] Yongsheng Su, Zhen Li, Liang Li, Jianbin Wang, Hong Gao, Gang Wang (2017). Cutting performance of micro-textured polycrystalline diamond tool in dry cutting. J Journal of Manufacturing Processes 27:1-7

[18] Rodrigo L, Stoeterau, Andreas Janssen, Guilherme Mallmann (2017). Analysis of dimple textured surfaces on cutting tools. J Journal of the Brazilian Society of Mechanical Sciences and Engineering 39:3989-3996

[19] Zhenglong Fang, Toshiyuki Obikawa (2017). Cooling performance of micro-texture at the tool flank face under high pressure jet coolant assistance. J Precision Engineering 49:41-51

[20] D. Vasumathy, AnilMeena (2017). Influence of microscale textured tools on tribological propertiesat 
tool-chip interface in turning AISI 316 austenitic stainless steel. J Wear 376-377:1747-1758

[21] Roshan Sasi, Kanmani SubbuS, I.A. Palani (2017). Performance of laser surface textured high speed steel cutting tool in machining of Al7075-T6 aerospace alloy. J Surface \& Coatings Technology 313:337-346

[22] Varun Sharma, Pulak M. Pandey (2016). Recent advances in turning with textured cutting tools: A review. J Journal of Cleaner Production 137:701-715

[23] Lei Wan, Dazhong Wang (2015). Numerical investigation of the dead metal zone with different tools in orthogonal cutting. J Simulation Modelling Practice and Theory 56:1-15

[24] Sener Karabulut (2015). Optimization of surface roughness and cutting force during AA7039/A12O3 metal matrix composites milling using neural networks and Taguchi method. J Measurement 66:139-149 